\title{
The influence of corrosion on bond properties between concrete and reinforcement in concrete structures
}

\author{
Anna Ouglova, Yves Berthaud, François Foct, Marc François, Frédéric Ragueneau, Ilie Petre-Lazar
}

\begin{abstract}
The rebar corrosion in reinforced concrete is one of the most extensive pathologies affecting the performance of concrete structures. Chloride-induced rebar corrosion damage results mainly from the use of de-icing salts in cold climates and/or exposure to marine environments. Carbonation damage is a further important degradation mechanism. The internal consequences of corrosion are the modification of the steel behavior and degradation of the steel-concrete bond. This work is devoted to the influence of the controlled corrosion on the adherence between steel and concrete. A new geometry of specimen has been designed to: (i) avoid the lateral confining stresses that appear during the classical pullout tests and (ii) permit
\end{abstract}

A. Ouglova · Y. Berthaud $(\bowtie) \cdot$ M. François ·

F. Ragueneau

LMT-Cachan (ENS Cachan/CNRS/Université Paris 6/

PRES-Sud), 61, avenue du Président Wilson,

94235 Cachan Cedex, France

e-mail: berthaud@lmt.ens-cachan.fr

M. François

e-mail: francois@lmt.ens-cachan.fr

F. Ragueneau

e-mail: ragueneau@lmt.ens-cachan.fr

A. Ouglova · F. Foct · I. Petre-Lazar

R\&D, MMC, Electricité de France, Site des Renardières,

Ecuelles, 77818 Moret sur Loing, France

A. Ouglova

e-mail: anna.ouglova@edf.fr

F. Foct

e-mail: francois.foct@1mt.ens-cachan.fr to impose a known confinement for the study of its influence on the behavior of the interface. Five specimens with different levels of corrosion have been tested in this contribution. Reinforcing bars embedded in concrete were submitted to accelerated corrosion using an external current source. The magnitude of corrosion was measured using both Faraday's law and the weight loss method. The level of corrosion varied from $0 \%$ to $0.76 \%$. The geometry of the specimens allowed us to take series of digital pictures during the tests, which were analyzed using a digital image correlation, the procedure named CORRELI $^{\mathrm{LMT}}$. The results of pullout tests proposed in this contribution indicate that: (i) levels of corrosion that are less than $0.4 \%$ of weight loss improves the bond stress and (ii) levels of corrosion resulting in more than $0.4 \%$ of weight loss lead to a reduction of the bond stress value.

Résumé La corrosion des armatures du béton armé est une des pathologies qui altèrent les performances des structures. La corrosion peut être provoquée par les sels de déverglaçage dans les zones soumises au gel et/ou aux embruns marins. La carbonatation constitue une autre source de dégradation. Les conséquences de cette corrosion sont la modification du comportement de l'acier et la dégradation de l'interface acier béton. Ce travail est consacré à l'analyse de l'influence de la corrosion contrôlée sur l'adhérence acier béton. Une nouvelle éprouvette a été imaginée afin (i) d'éliminer les contraintes 
latérales (de confinement) qui apparaissent dans les essais classiques d'arrachement et (ii) de pouvoir imposer ce confinement (par un système non décrit dans ce papier) pour l'étude de son influence sur le comportement de l'interface. Cinq éprouvettes avec différents taux de corrosion ont été testées dans ce travail. Les aciers ont été soumis à une corrosion accélérée par imposition d'un courant electrique. Le taux de corrosion a été mesuré à la fois par pesée et en utilisant la loi de Faraday. Le taux de corrosion utilisé dans cette étude varie de 0 à 0,76\%. La géométrie de l'éprouvette autorise la prise de clichés par une caméra CCD ; les analyses des images ont étéfaites avec le logiciel CORRELI ${ }^{L M T}$. Les résultats de ces nouveaux essais d'arrachement montrent que : (i) un taux de corrosion inférieur à 0,4\% ameliore les propriétés de l'interface acier béton, (ii) un taux de corrosion supérieur à cette valeur dégrade cette interface.

Keywords Corrosion - Concrete interface . Experiment $\cdot$ Identification

\section{Introduction}

The corrosion of reinforcements is one of the main causes of internal damage and of the ruining of reinforced concrete structures. The repair and rehabilitation of constructions affected by corrosion require considerable resources [1-3]. The consequence of corrosion appears as a reduction in the section of steel bar, a loss of bonding at a steelconcrete interface, a cracking of the concrete, and can, thus, cause a loss of mechanical capacity of the corroded structure.

Although considerable research has been conducted on the bond behavior of specimens with different levels of corrosion, little has been done to improve the representativeness of the mechanical tests with regard to the actual bond behavior [4]. The objective of this study, therefore, is to propose a new geometry of specimen that eliminates lateral stresses manifesting in the concentric pullout test and to assess the distribution of displacement and deformation fields during the test by using a digital image correlation technique. This new geometry that eliminates the lateral confinement also allows to impose very simply a known lateral pressure on the interface. It is presently used to study the effect of confinement on the behavior of the interface in the presence of corrosion on a flat bar or on ribbed bars.

Previous studies showed that the levels of corrosion increasing bond stress are still a matter of controversy. These levels vary from $1 \%$ to $4 \%$ of corrosion and depend on the conditions of the tests [1, 5-7]. However, all studies confirm that a further increase of the corrosion level decreases the bond stress quickly, which becomes insignificant for levels ranging between 3\% and 16\% (again with important scattering). This study provides additional information concerning the critical threshold of the corrosion level, which induces the decrease of bond stress.

Digital image correlation also provides other information about the displacement mode, bond stress, or of crack openings.

\section{Experimental program}

\subsection{Specimen}

Various tests have been proposed to assess bond characteristics in reinforced concrete structures. The selection of a proper specimen is still a matter of controversy and, until now, all popular used tests cannot represent fully the actual bond behavior.

For instance, in the specified concentric pullout test (ASTM C234 [8,9]), a bar is embedded in a prismatic concrete block and the force required to pull the bar out is measured. In this test, the measurement of the displacement between steel and concrete is carried out by a classical linear variable differential transformer (LVDT) [10-14]. Due to shrinkage, the concrete produces confinement around the rebar. Moreover, confining actions at the support of the testing machine introduce lateral stresses, which artificially increase the bond strength.

Other experimental investigations are the double tension test performed on ties [15-18] or the bond beam test [19-22] conducted on specimens of significant dimensions.

In order to improve the tests mentioned above, another pullout test (called the LMT test) has been designed in this investigation on a specimen with three bars embedded in a concrete plate. The geometry of the specimen and the experimental setup 
have been designed in order to eliminate the lateral stresses manifesting in the concentric pullout test. This test assesses the evaluation of displacement and deformation fields during the test by using a digital image correlation technique.

\subsubsection{Design of the specimen geometry}

The specimens, as well as the test arrangement, have been designed by taking into account the dimensions of an Instron testing machine. The chosen geometry is presented in Fig. 1. These windows are made during the molding process. Their presence allows the steel concrete interface to be observed by a CCD camera. As Teflon has been put around the central bar outside the zone corresponding to the window, the length concerned by the interface is only $12 \mathrm{~cm}$. The pullout load was applied through the free end of the central bar of the specimen. The two other bars were loaded in the opposite direction with respect to two bearings able to roll on a fixed beam, perpendicular to the loading direction, in order to avoid any lateral stress and parasite flexural actions.

The behavior of the specimen with three bars (LMT test) has been simulated using a 2D finiteelement code Castem in plane stress conditions. The mesh is presented in Fig. 2a. The bond was considered as perfect in this study as a first attempt to understand the interest of the present geometry. The non-linear part of the load displacement curve given by the computation is due to the non-linear behavior of concrete [11]. This non-linear behavior (due to the damage process) is initiated along the interface.

A simulation of the concentric pullout test was carried out in order to compare the evolution of

Fig. 1 Geometry of the LMT specimen
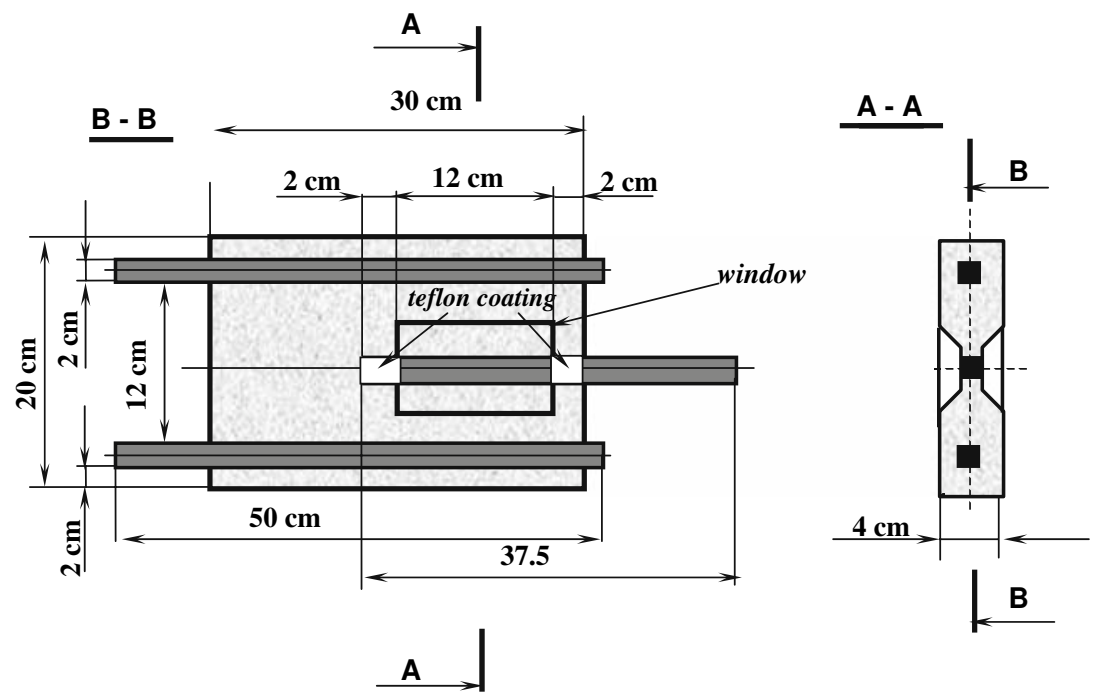

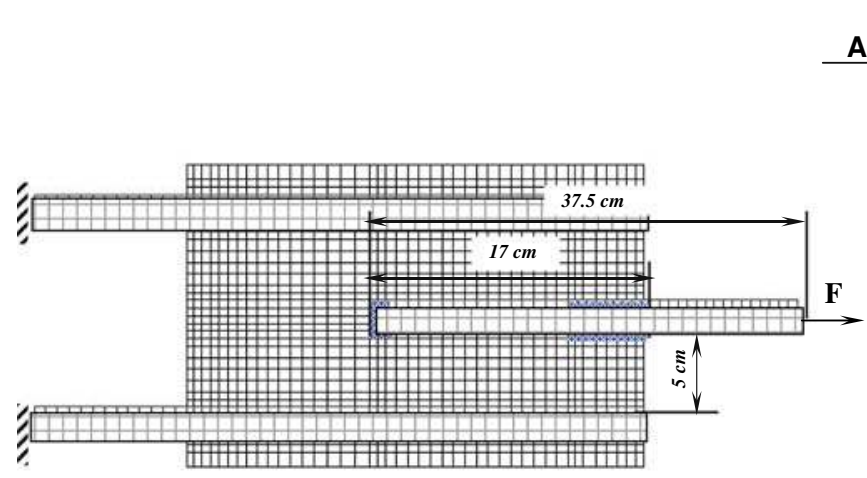

a) Pull-out test with three bars

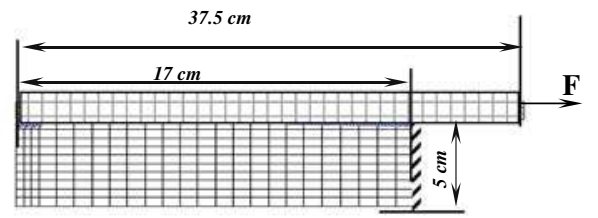

b)Concentric pull-out test

TConcrete element

Reinforcement element Bond free

Fig. 2 Meshes of the specimen 
lateral confining stress with the one of the proposed test. The simulation of the concentric pullout test was performed using a 2D finite-element code in axisymmetric conditions. The diameter of the bar is $2 \mathrm{~cm}$, the length of the bar embedded in concrete is $12 \mathrm{~cm}$, and the bond is perfect.

The models used to simulate the rupture of the reinforced concrete structure by a finite-element model are detailed hereafter:

- Intrinsic steel behavior. The constitutive equations retained for steel are elastic-perfectly plastic. The mechanical characteristics are the following: (i) Young's modulus of reinforcement $E s=200 \mathrm{GPa}$, (ii) $v=0.3$. The plasticity criterion has never been reached.

- Concrete behavior. The mechanical characteristics that have been deduced from various mechanical tests [23, 24,25] are the following: (i) Young's modulus of concrete $E c=30 \mathrm{GPa}$, (ii) compressive strength of concrete $f c=-$ $30 \mathrm{MPa}$, (iii) tensile strength of concrete $f t=2.2$ MPa. Mazars's model is chosen to describe the behavior of concrete as a non-linear model including a single damage variable [11].

Bond stress is calculated as the average normal stress between the reinforcing bar and the surrounding concrete along the embedded (and not coated) portion of the bar. The evolution of the average bond stress and concrete damage during the tests are presented in Fig. 3. Concerning the pullout test and the LMT test, the numerical simulation predicts the bond failure for the maximum mean bond stress to be equal to $3 \mathrm{MPa}$ and $7 \mathrm{MPa}(0 \%$ of corrosion), respectively.

In the case of the concentric pullout test with a smooth bar, the obtained ultimate bond stress corresponds well to those reported in [12]. Note that the LMT test leads to a decrease of the maximum average bond stress, which is a half as much as that of the concentric pullout test. This effect is only due to the difference in the state of stress around the bars. The decrease of the average bond stress is due to the damage of concrete inside the specimen and not to the degradation of the interface, which is not realistic.

Figure 4 shows the evolution of the lateral stresses along the bar (the interface is $0.12-\mathrm{m}$ long for the two specimens). We can observe that the plane stress conditions on the LMT specimen diminish "parasite" stresses that usually appear usually during the concentric pullout tests (Fig. 4). We can consider that, in practice, these normal stresses are negligible for the LMT test.

\subsubsection{Materials and mixture proportions}

A sand of Beaucaire (semi-crushed, silico-calcareous with a of granulometry $0.4 \mathrm{~mm}$ ), a cement of Beaucaire CEM1 $52.5 \mathrm{~N}$, and distilled water were used. The concrete mix contained $3.7 \mathrm{~kg}$ of sand, $1.7 \mathrm{~kg}$ of cement, and $0.8 \mathrm{~kg}$ of water. The w/c ratio was 0.46. A steel A56 was chosen for smooth rebars because it is representative of common steel used for reinforcements. In order to reduce the influence of the roughness, the central bar was mechanically polished,
Fig. 3 Average bond stress versus normalized displacement during the concentric pullout test and the LMT test without corrosion (1-damaged concrete, 2-non-damaged concrete)

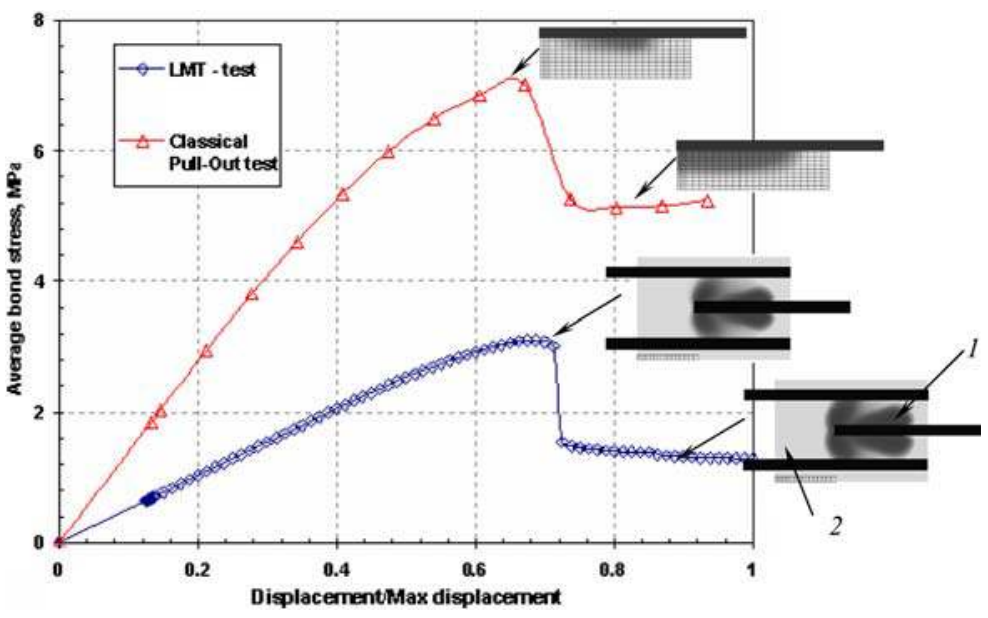




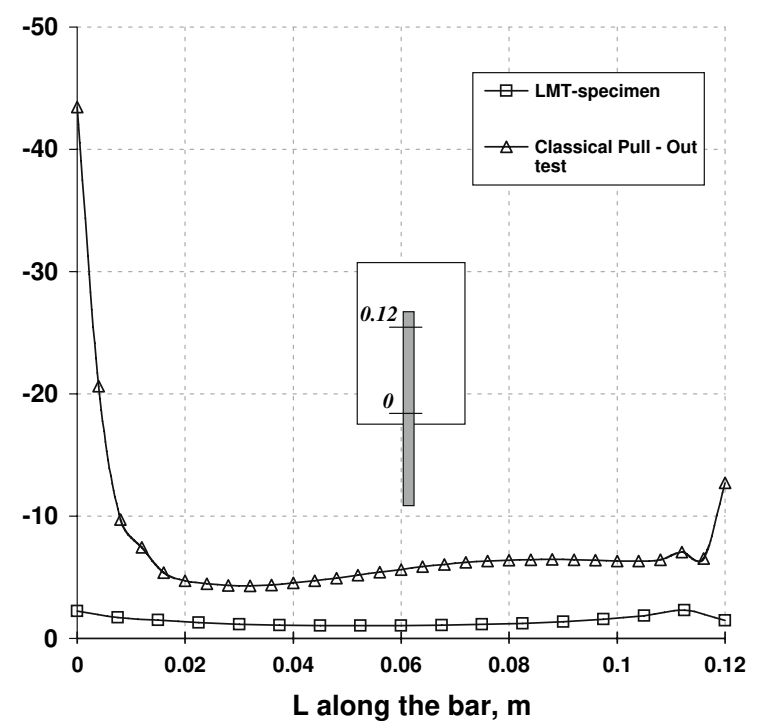

Fig. 4 Evolution of the lateral stress (MPa) during the concentric pullout test and the LMT test

degreased with acetone, and treated by a chemical attack with Parcodine 120 before being embedded in concrete. Each end of the embedded part of the bar was coated with Teflon to give an effective surface area of $48 \mathrm{~cm}^{2}$ in concrete. This mix is the mix we use at LMT, together with CEA, for all of the researches on corrosion. The order of magnitude of the mechanical properties range from $-40 \mathrm{MPa}$ up to $-30 \mathrm{MPa}$ for the compressive stress, from $2 \mathrm{MPa}$ to $3 \mathrm{MPa}$ for the tensile stress, and the Young modulus is always around $30 \mathrm{GPa}[23,24]$.

After the pouring of the concrete mix, an external vibrator was applied on the outer surface of the mold. At the end of casting, polyethylene sheets were used to cover the samples for the next $24 \mathrm{~h}$. The samples were demolded after $24 \mathrm{~h}$ and then cured over a week in a drying oven at $50^{\circ} \mathrm{C}$ with a relative humidity of $90 \%$ to accelerate its maturation.

\subsection{Current-induced corrosion process}

The known methods to accelerate corrosion are the following: (i) acceleration by a cyclic test with fog; (ii) acceleration by cycles wetting and drying, (iii) acceleration by electric current: an intense electrical current is applied between the reinforcement (anode) and the counter-electrode (cathode). The last method seems to be the one most often adopted to this study because it is the fastest method and it gives, moreover, a homogeneous corrosion on the surface of reinforcement but retains the induced corrosion level within the "natural" values that can be found in practice $[1,5,7]$. It is well known that accelerated corrosion does not give a correct representation of what happens in real cases (natural corrosion). The goal of the study is to examine the effects of the accelerated corrosion on the behavior of steel and of the interface so as to be capable of computing: (i) the time to inception of cracking due to corrosion and (ii) the carrying capacity of corroded structures using accelerated corrosion. Once the methodology is proved to be efficient, real cases will be studied.

Figure 5 shows the setup for the accelerated tests, which is composed of a current supply, an Ohm meter, an electric resistance, and a counter-electrode (cathode). The cathode is made of carbon fiber fabric (an excellent conductor which does not corrode and is practically not dissociated by the action of the electric field). A wet sponge provided the electrical contact between the specimen and the counter-electrode. To prevent the corrosion of the outer surface of the central bar embedded in the concrete, a Teflon coating was applied to these parts. The current density $\left(500 \mu \mathrm{A} / \mathrm{cm}^{2}\right)$ is applied through the counter-electrode located alternatively above or beneath the central bar of the specimen.

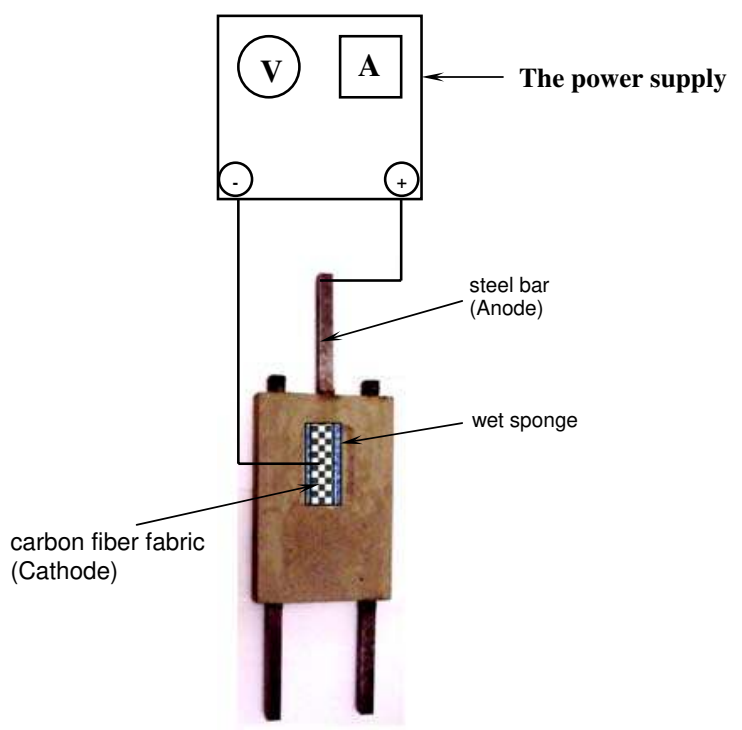

Fig. 5 Schematic representation of the electrochemical system 
The magnitude of corrosion was measured after mechanical testing using the loss of thickness of the steel, which can be easily converted to the level of corrosion (\%). The measurement of the loss of steel thickness rather than the level of corrosion was chosen because it is an intrinsic data source for the steel surface and does not depend on bar geometry. An attempt was made to induce corrosion up to $0.7 \%$ (loss of thickness $>40 \mu \mathrm{m}$ ), but the concrete cracked for this corrosion level. Faraday's law and the weight loss method are used to calculate the loss of thickness of steel of the bar, as well corrosion levels.

\subsubsection{Using Faraday's law to measure the loss of thickness provoked by corrosion}

The loss of thickness is related to the electrical current. The current $I_{\text {corr }}$ corresponds to the following chemical reaction:

$\mathrm{Fe}=>\mathrm{Fen}++$ ne -

The weight of lost material is:

$m=\frac{M \cdot I_{\text {corr }} \cdot t}{n \cdot F}$

The assumption is made that the section reduction is insignificant in comparison with the thickness, the lost thickness $e_{\text {corr }}(\mu \mathrm{m})$ is obtained by considering the density of iron $\rho=7.8 \mathrm{~g} / \mathrm{cm}^{3}$ :

$e_{\text {corr }}=\frac{M \cdot I_{\text {corr }} \cdot t}{\rho . n . F}$

where $M=55.85 \mathrm{~g} / \mathrm{mol}, \quad I_{\text {corr }}=0.5 \mathrm{~mA} / \mathrm{cm}^{2}$, and $F=96,500 \mathrm{C} \cdot \mathrm{mol}^{-1}$.

Assuming that the formed oxide is $\gamma-\mathrm{FeOOH}$, the estimated loss of thickness is obtained considering that, for each mole of iron oxidize, 3 moles of electrons are given out.

\subsubsection{Measurement of weight loss}

The central bars were extracted from specimens after mechanical tests. The mass of bars with oxides $\left(m_{\text {total }}\right)$ on the surface was measured with a scale of microgram accuracy. Then, the oxides were removed by a chemical dissolution [24, 27] and the bars were weighed again $\left(m_{\text {steel }}\right)$. The mass of oxides formed on surface is equal to: $m_{\text {oxide }}=\left(m_{\text {total }}-m_{\text {steel }}\right)+m_{\mathrm{ob}}$

where $m_{\mathrm{ob}}$ is the mass of oxides diffused into the concrete during the accelerated corrosion test. This mass cannot be measured or simply estimated. It has been decided to estimate the quantity both using image analysis and diffusion equations of the ions under the electrical field. This has been done for the 96-h specimen and the obtained ratio $m_{\mathrm{ob}} /\left(m_{\text {total }}-m_{\text {steel }}\right)$ has been kept constant for the other points. It has been shown previously that several iron compounds can be found in the corroded concrete structures $(\mathrm{Fe} 3 \mathrm{O} 4, \gamma$-Fe2O3, and $\alpha-\mathrm{FeOOH}$ ) [2]. Assuming that the oxides formed during the accelerated corrosion test are $\mathrm{FeOOH}$, so, taking into account the molecular mass of $\mathrm{FeOOH}$ $\left(M_{\text {oxide }}=88.85 \mathrm{~g} / \mathrm{mol}\right)$ and the iron $\left(M_{\mathrm{Fe}}=55.85 \mathrm{~g} /\right.$ mol), the mass of the bars before the accelerated corrosion test can be determined as follows:

$M_{\mathrm{Fe}}=\frac{m_{\text {oxide }} M_{\mathrm{Fe}}}{M_{\text {oxide }}}$

The lost thickness is obtained by the following equation:

$e_{\mathrm{corr}}=\frac{m_{\mathrm{Fe}}}{\rho \cdot S_{\mathrm{Fe}}}$

where $S_{\mathrm{Fe}}=96 \mathrm{~cm}^{2}$ is the area attacked by corrosion and $r$ is the density of the iron. The confidence interval was estimated taking into account the variation of $S_{\mathrm{Fe}} \pm 0.01 \mathrm{~cm}^{2}$ and $\rho \pm 0.01 \mathrm{~g} / \mathrm{cm}^{3}$.

\subsection{New LMT test}

These tests were carried out using an Instron testing machine under monotonic quasi-static load. The specially designed loading arrangement was fixed to the base of the machine. The setup of these tests is presented in Fig. 6. The contact between the two parallel bars of the specimen with the machine were obtained by the connections of a ball-joint type to avoid any parasitic effect (bending of the specimen). The pullout load was applied through the free end of the central bar of the specimen. The bond displacement response between the concrete and the central bar was measured using two LVDT, which were placed on the top and the bottom of the specimen (Fig. 6). The tensile loading was monitored by a load cell placed above the free end of the central bar. So, 
Fig. 6 Setup of the pullout test

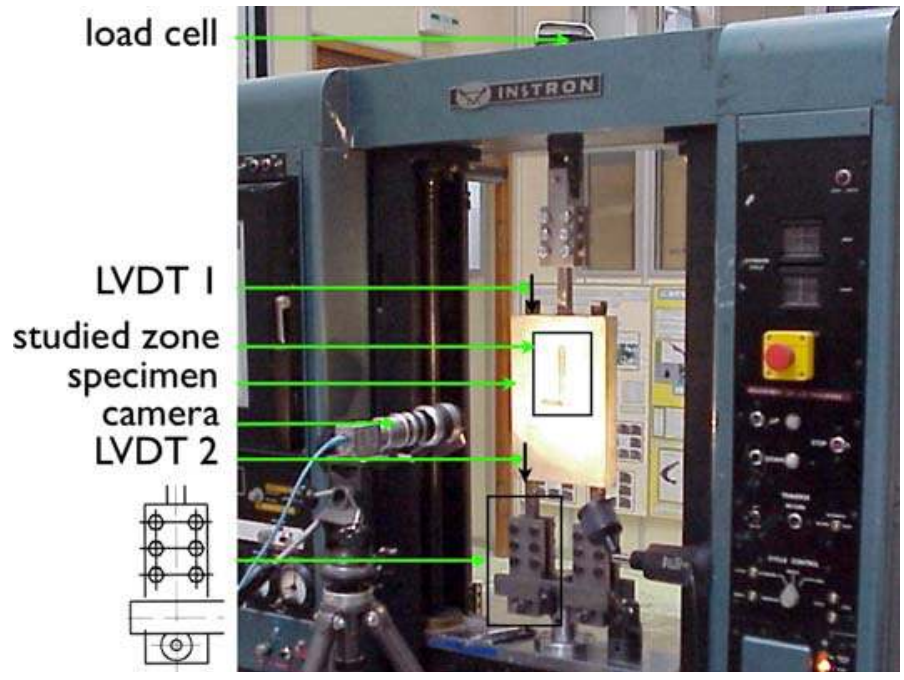

the load and the displacement were acquired using a data logger and the load and displacement readings were recorded at preset intervals.

A 10.5-bit CCD camera $(1,024 \times 1,024$ pixels $)$ was used to record pictures in the studied zone during the test. The series of pictures taken during the tests were analyzed using a digital image correlation, the procedure CORRELI $^{\mathrm{LMT}}$ [26]. This procedure is implemented in Matlab $^{\text {TM }}$. The applied technique is based upon a multi-scale approach, which allows the determination of the displacement and deformation fields.

The aim of this method is to look for the maximum correlation between the small zones extracted from the "deformed" and reference images.

Firstly, to determine the average displacement, an inscribed region of interest (ROI) centered on the reference image should be chosen (see Fig. 7). The same ROI is considered in the deformed image. If we suppose that the local transformation between the two configurations is a simple translation, we have to determine the two components (in-plane displacement) $x$ and $y$. Let us suppose the signal in the second configuration to be $\mathrm{g}(\xi, \psi)$, which is a copy shifted by $\mathrm{f}(\xi-x, \psi-y)$ of the original signal $\mathrm{f}(\xi, \psi)$. The unknown displacements $x$ and $y$ are found as the maximum of the cross-correlation product $h$.

$$
\begin{aligned}
h(x, y) & =(g \Theta f)(x, y) \\
& =\int_{-\infty}^{+\infty} \int_{-\infty}^{+\infty} g(\xi, \psi) f(\xi-x, \psi-y) \mathrm{d} \xi \mathrm{d} \psi
\end{aligned}
$$

A first correlation is performed to determine the average displacement. This displacement vector is expressed by an integer number of pixels and is obtained as the maximum of the cross-correlation function evaluated for each pixel of the ROI. This
Fig. 7 Principle of digital correlation

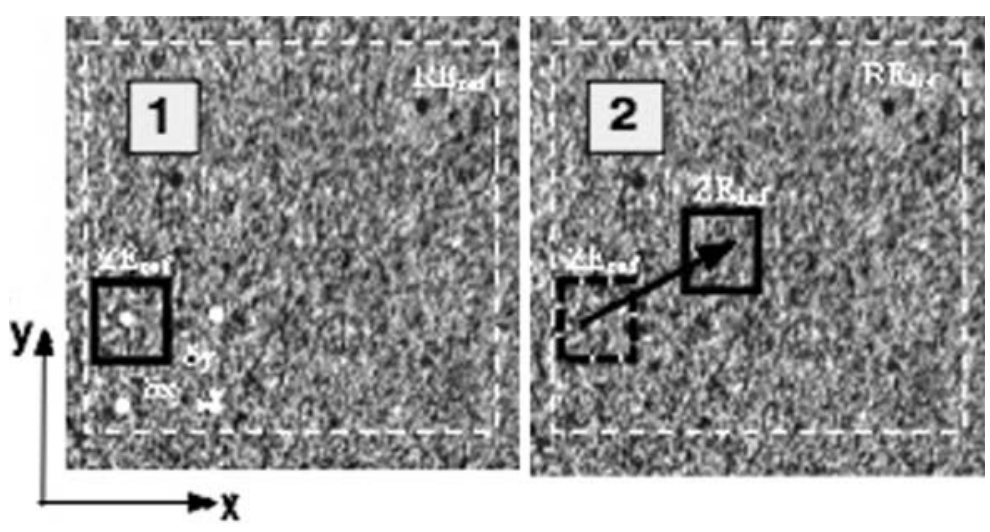


first prediction enables us to determine the maximum number of pixels that belong to both images. The ROI in the deformed image is now centered at a point corresponding to the displaced center of the ROI in the reference image.

Secondly, the analysis of a displacement field is obtained for different positions of the zone of interest (ZOI). The ZOI (black dashed square) is a sub-image of the ROI. A first correlation is carried out and a first value of the in-plane displacement correction is obtained. The analysis is then performed for each ZOI independently using a multi-scale correlation algorithm. More details of this approach are presented in [26]. Of course, this technique is only applicable to our specimen because of the geometry (plate) and assuming that no out-of-plane displacement occurs. The classical parameters used are: $1,024 \times 1,024$ pixel images with a 12-bit signal, $32 \times 32$ pixels ZOI. The technique (in particular, the computations in the Fourier space and the various signal processing ingredients) allow the determination of $3 / 100$ pixel displacement, which means a value of $10^{-4}$ as the minimum strain detectable by the optical set-up.

\section{Test results and discussion}

The test results were analyzed to obtain information on the following parameters: (i) comparison of theoretical and loss weight approaches; (ii) bond behavior with respect to corrosion level; (iii) evolution of the displacement and deformation fields.

The test results of the digital image correlation indicate that the multi-scale approach can be successfully used to provide information about the evolution of the displacement and deformation fields in the specimen during mechanical testing.

\subsection{Comparison of the theoretical and measured weight loss}

As mentioned above, the corrosion mass loss can be computed using the amount of electrical energy sent through the bar (Eq. 1). In this approach, it is assumed that corrosion starts as soon as the electrical energy is applied. But in the concrete reinforcing structures, it is necessary to take into account that a certain amount of energy is needed to initiate the corrosion [1].

The results of the thickness loss and corrosion levels obtained using the weight loss approach are presented in Table 1. It should be noted that the level of corrosion does not exceed $0.76 \%$ because of the cracking of concrete up to $0.7 \%$. So, the specimen corroded during $96 \mathrm{~h}$ was fully cracked before testing.

A comparison of the theoretical and weight loss approaches is given in Fig. 8. It shows a reasonable agreement between the results of the weight loss method and those found by the Faraday's law (and the $n=3$ value).

\subsection{Effect of corrosion on the displacement and ultimate bond stress}

The average bond stress-displacement curves for five levels of corrosion are plotted in Fig. 9. Firstly, the value of the average bond stress of the non-corroded specimen is equal to $0.5 \mathrm{MPa}$. It has been shown previously that this value is about $1 \mathrm{MPa}$ in the case of the axial pullout test with different conditions of steel-concrete interface and when the smooth bar is well polished [12]. Recently, we found 1.1-1.3-MPa values for this pullout test and similar conditions (both in geometry and concrete composition) [23]. If we consider the ratio between the two mean values that is given by the numerical analysis to be equal to 2 , we can conclude that this $0.5-\mathrm{MPa}$ bond stress is acceptable.

Then, it can be seen that the stress-displacement curve for the specimen with a non-corroded bar shows a linear relationship up to $0.4 \mathrm{MPa}$. Thereafter, the stress-displacement curve exhibits a significantly increased displacement without any changes in the stress.

Secondly, Fig. 9 shows that the maximal average bond stress increases with a corrosion level of less than $0.36 \%\left(e_{\text {corr }}=10.45 \mu \mathrm{m}\right)$. It has been observed by some researchers that the surface of the bar becomes rougher by the products of corrosion for small levels of corrosion, which increases friction between the bar and the surrounding concrete. Also, the pressure provoked by the growth of oxides in the 
Table 1 Results of the thickness loss and corrosion levels obtained using the chemical dissolution of oxides

\begin{tabular}{lcccr}
\hline Duration of accelerated corrosion (hours) & 8 & 48 & 56 & 96 \\
\hline$m_{\text {total }}(\mathrm{g})$ & $1,166.66$ & $1,167.04$ & $1,168.54$ & $1,169.92$ \\
$m_{\text {steel }}(\mathrm{g})$ & $1,165.42$ & $1,164.88$ & $1,166.12$ & $1,165.37$ \\
$m_{\text {oxide }}(\mathrm{g})$ & 1.245 & 2.16 & 2.425 & 4.55 \\
Weight of Fe corroded $(\mathrm{g})$ & 0.78 & 1.358 & 1.52 & 2.86 \\
$e_{\text {corr }}(\mu \mathrm{m})$ & 10.45 & 18.132 & 20.357 & 38.195 \\
Level of corrosion $(\%)$ & 0.2 & 0.36 & 0.4 & 0.76 \\
\hline
\end{tabular}

steel-concrete interface tends to increase the reactionary confinement and the mechanical interlocking of concrete around the bar [4]. The specimens with $0.2 \%$ and $0.35 \%$ levels of corrosion have a linear behavior between the mean bond stress (i.e., load) and displacement up to almost the ultimate bond stress.

When the level of corrosion reaches $0.4 \%\left(e_{\text {corr }}=\right.$ $20.36 \mu \mathrm{m})$, the maximal average bond stress decreases quickly to become negligible. This is due to the presence of a thick enough layer of corrosion products at the steel-concrete interface, as well as the debonding of this interface in the case of the specimen of $0.76 \%$ of corrosion. Considerable displacement occurred at the ultimate load stage and a change of the bond stiffness is observed.

It was concluded that two stages were observed: (i) increase of the maximal average bond stress up to $0.4 \%$ of corrosion and (ii) decrease of this stress after $0.4 \%$ of corrosion. A comparison of these results with those obtained using the concentric pullout test [5] in the case of slightly corroded specimens shows that the critical threshold of increase of the maximal average bond stress decreases from $1-4 \%$ to $0.4 \%$

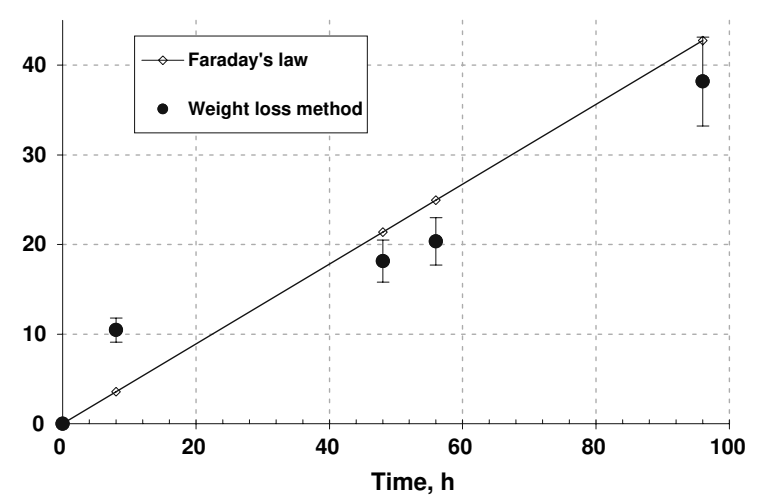

Fig. 8 Thickness loss $e_{\text {corr }}(\mu \mathrm{m})$ v.s. time for theoretical and experimental approaches

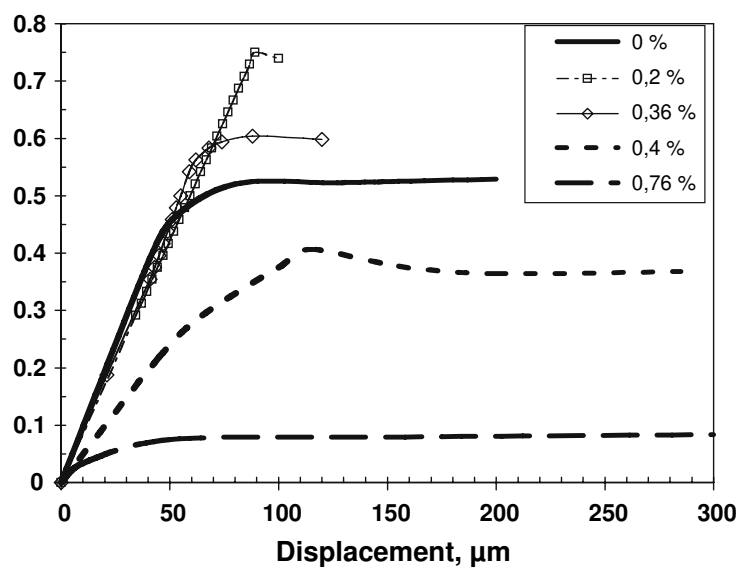

Fig. 9 Effect of corrosion on bond stress (MPa)-displacement behavior (displacement given by LVDT1-Fig. 6)

(LMT test). It is probably due to the reduction of lateral parasite stresses in the LMT test, which usually occurs in the concentric pullout test.

\subsection{Visualization of the displacement and deformation fields by using analysis of images}

The purpose of the digital image correlation is to study the localization of the bond failure at the steelconcrete interface during the mechanical testing. Series of pictures were taken during the LMT test. Then, these digital pictures were analyzed using the CORRELI $^{\text {LMT }}$ procedure [27].

For the uncorroded bar, the ROI is given in Fig. 10a (the width of the bar is $2 \mathrm{~cm}$ ). A sequence of 11 pictures was taken during this test. Figure $10 \mathrm{a}, \mathrm{b}$ give the iso-values of axial displacement, called UX (in the direction of the applied load) between two stages (0.3 MPa and $0.45 \mathrm{MPa}$ mean stress). It appears to be possible to observe the stage corresponding to the inception of bond failure. The iso- 


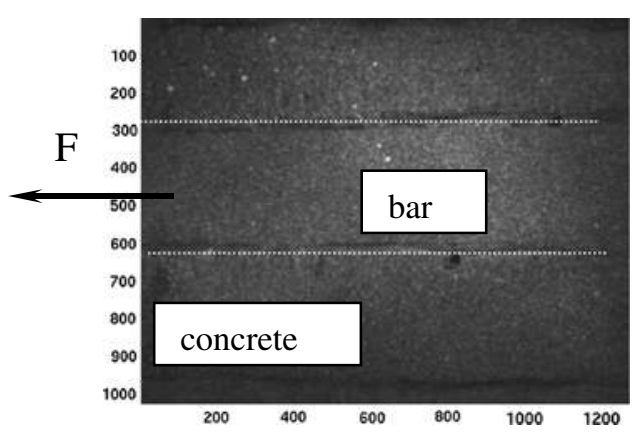

a) Reference image

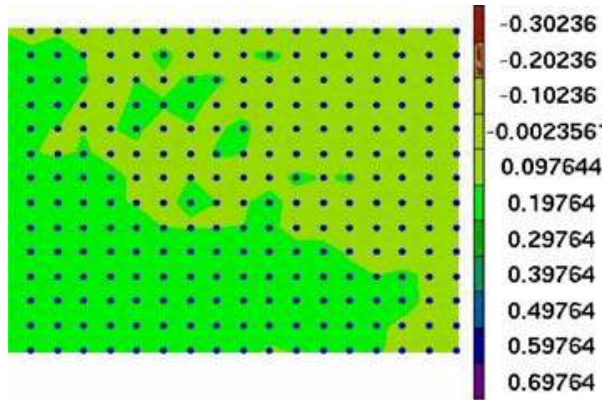

b) Iso-values of displacement UX in pixels (average bond stress $=0.3 \mathrm{MPa}$; 1 pixel $=0.005 \mathrm{~cm}$ )

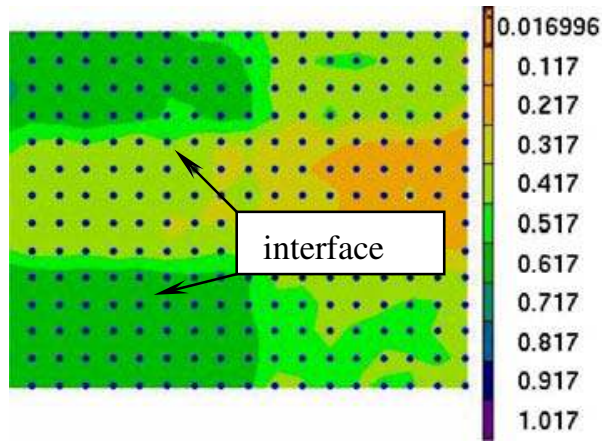

c) Iso-values of displacement UX in pixels (average bond stress $=0.45 \mathrm{MPa}$ )

Fig. 10 Results of the digital image correlation in the case of a specimen with an uncorroded bar

values of Fig. 10c around the bar exhibit a discontinuity of displacement along the interface (i.e., for the portion of the bar close to the applied load). Thus, there is a relative displacement of the reinforcement in the concrete and this is for an average bond stress $(0.45 \mathrm{MPa})$ lower than the maximum value $(0.5 \mathrm{MPa})$. The same iso-values of displacement between the initial state (the reference image) and the state of Fig. 10b (0.3 Mpa) are continuous, so, there is still an adherence between the reinforcement and the concrete.

Concerning the specimen with $0.2 \%$ of corrosion, the same distribution of iso-values of displacement and deformation were observed for that in the case of the specimen with the non-corroded bar. However, the average bond stress $(0.29 \mathrm{MPa})$ of the relative displacement of the reinforcement is almost $40 \%$ lower than the maximum value $(0.75 \mathrm{MPa})$ found during the LMT test. It seems that the increase in the level of corrosion introduces a cracking at the steel- concrete interface early in the test. It can be said that the movement of the corroded layer of the reinforcement with increasing load as well as the pressure caused by expansive corrosion product dominates the micro-cracking at the steel-concrete interface and leads to an increase of the maximum average bond stress with respect to some Coulomb's mechanism.

Two specimens with $0.36 \%$ and $0.4 \%$ of corrosion show a similar distribution of iso-values of displacement and deformation during the tests. So, only the behavior of the specimen with $0.36 \%$ of corrosion is discussed hereafter.

Figure 11 gives a reference image of the specimen with $0.36 \%$ of corrosion. In this test, the magnitude of the chosen zone was twice as much as the one of the specimen with $0 \%$ corrosion. The distribution of isovalues of displacement UX and the iso-values of deformation EYY (computed with a virtual (or optical) gauge length equal to the length of the ZOI, i.e., 64 pixels in this case) show two 


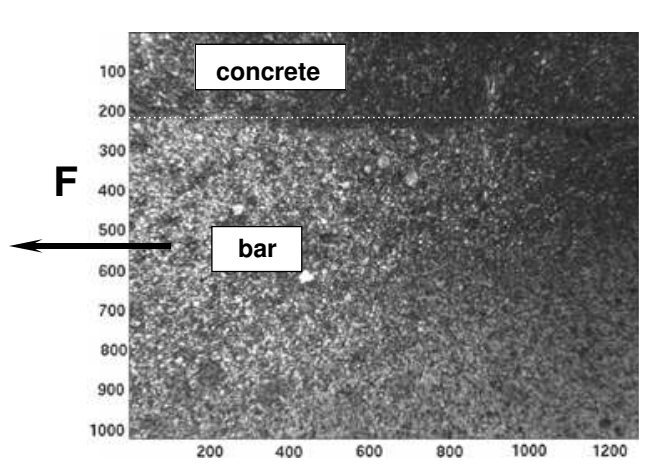

a) Reference image

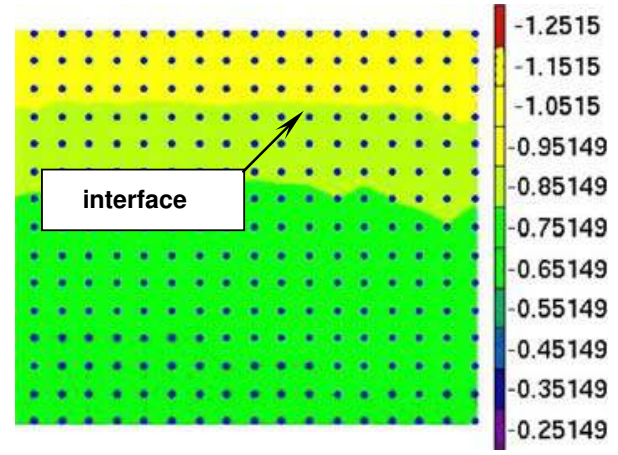

b) Iso-values of displacement UX in pixels (average bond stress $=0.125 \mathrm{MPa})$

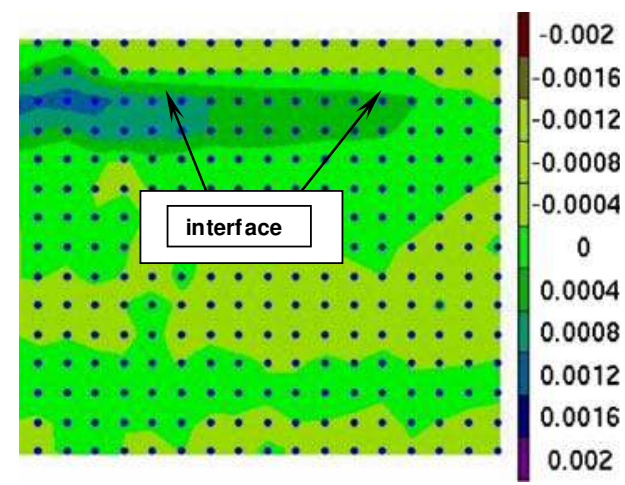

c) Iso-values of deformation EYY (average bond stress $=0.125 \mathrm{MPa}$ )

Fig. 11 Results of digital image correlation in the case of a specimen with $0.36 \%$ of corrosion

competitive modes of crack opening (Fig. 11c). It seems that the increase of the level of corrosion products up to $0.36 \%$ at the steel-concrete interface leads clearly to the opening of cracks in the perpendicular direction to that of loading (it is visible with respect to intense strain normal to the interface). This can be explained by the influence of cohesion between particles of oxides as well as by the angle of friction that is often observed during compression tests on sand (or such cohesive and granular materials). The beginning of the relative displacement of the reinforcement arises while bond stress is around $0.125 \mathrm{MPa}$ for the specimen with $0.36 \%$ corrosion and $0.08 \mathrm{MPa}$ for that with $0.4 \%$ are less than the peak values recorded during the test. In the case of the specimen with $0.76 \%$ of corrosion, the first image compared with the reference image illustrates the bond failure.

These measurements helped us to precisely identify the inception of cracking of the interface by simply detecting the transition between the homogeneous response and the localized response (in the sense of interface opening and/or sliding). Of course, the observed zone is limited by the CCD resolution and the small displacements or deformation to be measured. Any how, we can assert that the "local" bond stress to be used is lower than that corresponding to the macroscopical transition between the linear and non-linear regimes.

\section{Conclusions}

Based on the results reported in this paper and the observations made during the experimental investigation, the following conclusions can be offered:

- The levels of corrosion of five specimens have been defined with good agreement by using both Faraday's law and weight loss method. 
- The results of LMT tests show that the bond stress is significantly affected by the corrosion level.

- The slight corrosion levels of up to $0.4 \%$ increase the values of the average bond stress and bond stiffness.

- When the corrosion level exceeds $0.4 \%$, the bond stress and bond stiffness decrease considerably. When the level of corrosion is equal to $0.76 \%$ and the cracking of concrete takes place, the bond is not completely destroyed.

- The digital image correlation provides information about the inception of bond failure (in the zone observed by the CCD). It indicates that the increase of corrosion level introduces a significant decrease of the onset of bond failure. The average bond stress corresponding to the beginning of the relative displacement of the reinforcement in the concrete is less than the maximum stress recorded during the test.

- The increase of corrosion levels greater than $0.36 \%$ lead clearly to "interface opening" normal to the interface.

\section{References}

1. Auyeung YB, Balaguru P, Chung L (2000) Bond behavior of corroded reinforcement bars. ACI Mater J 97(2):214-220

2. Stanish K, Hooton RD, Pantazopoulou SJ (1999) Corrosion effects on bond strength in reinforced concrete. ACI Struc J 96(6):915-921

3. Almusallam AA (2001) Effect of degree of corrosion on the properties of reinforcing steel bars. Constr Build Mater 15:361-368

4. Almusallam AA, Al-Gahtani AS, Aziz AR, Rasheeduzzafart (1996) Effect of reinforcement corrosion on bond strength. Constr Build Mater 10:123-129

5. Cabrera JG (1996) Deterioration of concrete due to reinforcement steel corrosion. Cement Concrete Comp 18:4759

6. Sulaimani GJ, Kaleemullah K, Basunbul IA, Rasheeduzzafar M (1990) Influence of corrosion and cracking on bond behavior and strength of reinforced concrete members. ACI Struct J 87:220-231

7. Lee H-S, Noguchi T, Tomosawa F (2002) Evaluation of the bond properties between concrete and reinforcement as a function of the degree of reinforcement corrosion. Cement Concrete Res 32:1313-1318

8. American Society for Testing and Materials (ASTM) (1991) Standard test method for comparing concretes on the basis of the bond developed with reinforcing steel. C234-91a

9. Lutz LA, Gergely P, Winter G (1966) The mechanics of bond and slip of deformed reinforcing bars in concrete.
Structural Engineering report no. 324, August 1966, Cornell University, Ithaca, New York

10. Coronelli D, Gambarova PG, Ravazzani P (2001) Size effect in steel-concrete bond: test results and modelling for smooth bars. In: Proceedings of the 4th International Conference on Fracture Mechanics of Concrete Structures (FraMCoS), Cachan, France, May/June 2001, pp 669-676

11. Mazars J (1986) A description of micro- and macroscale damage of concrete structures. J Eng Fract Mech 25:729-737

12. Ihekwaba NM, Hope BB, Hansson CM (1996) Pull-out and bond degradation of steel rebars in ECE concrete. Cement Concrete Res 26:267-282

13. Eligehausen R, Popov EP, Bertero VV (1983) Local bond stress-slip relationships of deformed bars under generalized excitations. Report no. UCB/EERC-83/23 of the National Science Foundation, University of California, Berkeley, California

14. Malvar LJ (1992) Bond reinforcement under controlled confinement. ACI Mater J 89(6):593-601

15. Goto Y (1971) Cracks formed in concrete around deformed tension bars. ACI J 68(4):244-251

16. Jaccoud J-P (1987) Armature minimale pour le contrôle de la fissuration des structures en béton. Thèse de l'EPF de Lausanne, Switzerland

17. Clément JL (1987) Interface acier-béton et comportement des structures en béton armé: caractérisation-modélisation. Thèse de l'Université Paris VI, France

18. Daoud A (2003) Etude expérimentale de la liaison entre l'acier et le béton auto-plaçant-contribution à la modélisation numérique de l'interface. Thèse de l'INSA de Toulouse, France

19. Molina M, Gutierrez JP, Garcia MD (2002) Evaluation of reinforced concrete structures with partial loss of concrete/ steel bond. In: Proceedings of the International Conference "Bond in Concrete" held at the Budapest University of Technology and Economics, Budapest, Hungary, November 2002, pp 182-189

20. Turk K, Caliskan S, Yildirim MS (2005) Influence of loading condition and reinforcement size on the concrete/reinforcement bond strength. Struct Eng Mech 19(3):337-346

21. Balazs GL, Koch R (1995) Bond characteristics under reversed cyclic loading. Otto Graf J 6:47-62

22. Foo EL (1998) An alternative test for bond strength of concrete reinforcing bars. Michigan Technical University, Houghton, Michigan

23. Tran BH (2005) Evaluation de l'adhérence acier-béton: identification de l'effet de la contrainte normale. Master of Civil Engineering report, ENS Cachan/UPMC, France

24. Ouglova A (2004) Etude du comportement mécanique des structures en béton armé atteintes par la corrosion. Thèse de l'ENS de Cachan, France

25. Nguyen QT (2007) Etudes expérimentale et théorique de l'effet de la corrosion sur la fissuration du béton et le comportement global des structures en béton armé. Thèse de l'Université P\&M Curie, Paris, France

26. International Organization for Standardization (ISO) (1991) Removal of corrosion products from corrosion test specimens. ISO 8407:1991

27. Hild F (2002) CORRELILMT: a software for displacement field measurements by digital image correlation. Internal report no. 254, LMT-Cachan, France 